\section{AVALIAÇÃO DO DESEMPENHO DE GRAUTES DE REPARO, SEM E COM ADIÇÃO DE PEDRISCO, QUANTO À FLUIDEZ E RESISTÊNCIA MÊCANICA}

\section{SOARES, JOÃO}

Graduando Engenharia Civil

Centro Universitário Uniopet

Paraná, Brasil

j.gui1@hotmail.com

\section{MENDES, SANDRO}

Professor MSc. Eng. Civil

Centro Universitário Uniopet

Paraná, Brasil

sandromendes2005@gmail.com

\author{
GASPARINI, THIAGO \\ Graduando Engenharia Civil \\ Centro Universitário Uniopet \\ Paraná, Brasil \\ thiago_engprod@outlook.com
}

\section{RESUMO}

Este artigo analisou três marcas de grautes diferentes. Os grautes foram avaliados quanto a sua fluidez no estado fresco, e quanto ao desempenho mecânico no estado endurecido. Devido à falta de uma normalização nacional para caracterizar e padronizar os grautes industrializados mediante ensaios de fluidez, foi adotada a norma NBR 15823:2017, uma vez que o graute com pedrisco assemelha-se a um concreto auto adensável. Para os ensaios no estado endurecido foram determinadas as resistências à compressão simples (NBR 5739:2018), tração por compressão diametral (NBR 7222:2011) e tração na flexão (NBR 13279:2005). Em relação à fluidez, todos os grautes cumpriram as especificações da norma e se caracterizaram como autoadensáveis. Em relação ao desempenho mecânico, nenhum dos grautes atendeu $100 \%$ as resistências especificadas pelo próprio fabricante. Com base nos resultados obtidos, o pedrisco influenciou tanto nos ensaios no estado fresco, quanto nos ensaios no estado endurecido.

Palavras-chave: graute, pedrisco, fluidez, resistência.

\section{ABSTRACT}

This article analyzed three different grout marks. These grouts were evaluated for their fluidity in the fresh state, and for mechanical performance in the hardened state. Due to the lack of national standardization to characterize and standardize industrialized grouts through fluidity tests, the NBR 15823:2017 standard was adopted, since the grout with gravel resembles a self-compacting concrete. For the hardened state tests were determined the simple compressive strengths (NBR 5739: 2018), tensile compression diametral (NBR 7222: 2011); and flexural traction (NBR 13279: 2005). Regarding fluidity, all grouts met the specifications of the standard and were characterized as self-compacting. Regarding the mechanical performance, none of the grouts met $100 \%$ the compressive strength specified by the manufacturer. Based on the results obtained, the gravel influenced both the tests in the fresh state and the hardened state.

Keywords: grout, gravel, fluidity, strength.

\section{INTRODUÇÃO}

O graute, com ou sem a adição do pedrisco, é atualmente um material que na construção civil tem sido muito utilizado devido a capacidade de realizar reparos nas estruturas ou para simplesmente ser usado como um elemento de reforço. Destacam-se no graute as elevadas resistências e excelente fluidez. 
Segundo Tula, Oliveira e Helene (2002), para que as argamassas ou concretos sejam considerados grautes, estes devem possuir uma consistência fluida, de forma que sejam auto adensáveis. E garantir valores altos de resistências iniciais e finais.

O trabalho apresenta uma análise comparativa das especificações de grautes para reparos encontrados no mercado atualmente, e caracterizar três amostras de grautes de fabricantes diferentes (graute A, graute B e graute C) verificando suas resistências à compressão às $24 \mathrm{~h}, 3$ dias, 7 dias, 14 dias e 28 dias e tração em corpos de prova cilíndricos e prismáticos, verificando também suas consistências para avaliar a fluidez e se cumprem com as especificações dos próprios fabricantes. Outro objetivo é avaliar a influência que o pedrisco tem nas resistências dos materiais, já que a adição do agregado é utilizada para aumentar o volume do graute, diminuindo seu custo por $\mathrm{m}^{3}$. E por fim, citar a importância de uma normalização para o graute de reparo, pois foram utilizadas normas de CAA (Concreto Auto Adensável) para esse estudo, haja vista não existam normas brasileiras que os especifiquem.

\section{METODOLOGIA}

Os grautes para estudo foram selecionados entre os disponíveis no mercado da região, com a mesma finalidade de aplicação - reparos e auto adensável - sendo então grautes semelhantes entre si no quesito fluidez e resistência mecânica. Foram utilizados 3 grautes de fabricantes diferentes com características semelhantes e resistências entre 40 e $50 \mathrm{MPa}$.

Utilizou-se para as dosagens água potável da rede de abastecimento Sanepar. As dosagens dos grautes sem e com pedrisco foram realizadas obedecendo as especificações de cada fabricante estão de acordo com a Tabela 1:

Tabela 1 - Dosagens dos Grautes

\begin{tabular}{|c|c|c|}
\hline Grautes & Sem pedrisco & Com pedrisco \\
\hline A & $\begin{array}{l}3 \mathrm{~L} \text { de água a cada } 25 \mathrm{~kg} \text {; Adicionar } 2 / 3 \text { de água e } \\
\text { misturar por } 3 \text { min, a seguir adicione o restante da } \\
\text { água e misture por mais } 3 \text { min. }\end{array}$ & $\begin{array}{l}\text { Seguir a mesma recomendação da mistura } \\
\text { pura, porém, adicionar } 30 \% \text { de pedriscos ou } \\
\text { brita } 0 \text {. }\end{array}$ \\
\hline B & $\begin{array}{l}3,5 \mathrm{~L} \mathrm{de} \mathrm{água} \mathrm{a} \mathrm{cada} 25 \mathrm{~kg} \text {; Adicionar } 2 / 3 \text { de água } \\
\text { e misturar por } 3 \text { min, a seguir adicione o restante } \\
\text { da água e misture por mais } 3 \text { min. }\end{array}$ & $\begin{array}{l}\text { Seguir a mesma recomendação da mistura } \\
\text { pura, porém, adicionar } 30 \% \text { de pedriscos ou } \\
\text { brita } 0 \text {. }\end{array}$ \\
\hline $\mathrm{C}$ & $\begin{array}{l}3 \mathrm{~L} \text { de água a cada } 25 \mathrm{~kg} \text {; Adicionar } 2 / 3 \text { de água e } \\
\text { misturar por } 3 \text { min, a seguir adicione o restante da } \\
\text { água e misture por mais } 3 \mathrm{~min} .\end{array}$ & $\begin{array}{l}3,25 \mathrm{~L} \text { de água a cada } 25 \mathrm{~kg} \text {; Adicionar } 2 / 3 \\
\text { de água e misturar por } 3 \mathrm{~min} \text {, a seguir } \\
\text { adicione o restante da água e misture por } \\
\text { mais } 3 \text { min; Utilizar então } 30 \% \text { de pedrisco } \\
\text { ou brita } 0 \text {. }\end{array}$ \\
\hline
\end{tabular}

Para os ensaios no estado endurecido, mostra-se o planejamento para os grautes $\mathrm{A}, \mathrm{B}$ e $\mathrm{C}$ considerando as resistências à compressão, tração por compressão diametral, tração na flexão e o quantitativo dos corpos de prova (CP's) por idade, conforme Tabela 2 abaixo.

Tabela 2 - Planejamento dos ensaios e quantitativo dos corpos-de-prova

\begin{tabular}{|c|c|c|c|c|c|}
\hline Ensaio realizado & Grautes A, B e C & Idades (dias) & $\mathrm{CP} /$ Idade & Quant. & Total \\
\hline \multirow{5}{*}{ Resistência à compressão } & \multirow{5}{*}{ Sem/Com Pedrisco } & 1 & 2 & 12 & \multirow{5}{*}{60} \\
\hline & & 3 & 2 & 12 & \\
\hline & & 7 & 2 & 12 & \\
\hline & & 14 & 2 & 12 & \\
\hline & & 28 & 2 & 12 & \\
\hline $\begin{array}{l}\text { Resistência à tração por } \\
\text { compressão diametral }\end{array}$ & Sem/Com Pedrisco & 28 & 2 & 12 & 12 \\
\hline $\begin{array}{l}\text { Resistência à tração na } \\
\text { flexão }\end{array}$ & Sem/Com Pedrisco & 28 & 4 & 24 & 24 \\
\hline \multicolumn{5}{|c|}{ al de corpos de prova: } & 96 \\
\hline
\end{tabular}


Foram moldados para o ensaio de resistência à compressão, 10 CP's sem pedrisco e 10 CP's com pedrisco. Totalizando $20 \mathrm{CP}$ 's para cada marca de graute, ou seja, um total de $60 \mathrm{CP}$ 's. Referente à resistência a tração por compressão diametral, foi realizado apenas o ensaio aos 28 dias, e usou-se apenas 2 CP's para cada mistura (com e sem pedrisco), sendo 4 CP's x 3 marcas de graute, totalizando 12 CP's. Na resistência à tração na flexão, os corpos de prova foram ensaiados conforme a NBR 13279:2005, estabelecendo 4 CP's sem pedrisco e 4 CP's com pedrisco para cada amostra de graute, sendo 8 CP's x 3 marcas de graute, totalizando 24 CP's.

Para avaliar as propriedades dos grautes no estado fresco, foram estabelecidos os ensaios normatizados na ABNT NBR 15823 (2017), aplicados ao concreto auto adensável (CAA) justificando-se, ao adicionar pedrisco, o graute se assemelha ao CAA, e segundo os fabricantes, a adição do agregado não afeta sua fluidez e resistência mecânica com a adição máxima de 30\%. Foram realizados o slump flow, caixa L, caixa U e funil V.

\section{RESULTADOS}

A seguir, apresentam-se a caracterização do pedrisco utilizado nas dosagens e as análises dos resultados no estado fresco e endurecido. Os resultados obtidos foram comparados com as especificações fornecidas pelos fabricantes.

\subsubsection{Caracterização do agregado graúdo}

Para a caracterização do agregado graúdo, foi estabelecido conforme norma NBR NM 248:03. No Gráfico 1 as linhas "traço e ponto" mostram os limites granulométricos da brita 0 conforme a Norma NBR 7211:2009.

Gráfico 1 - Curva granulométrica do agregado (brita 0)

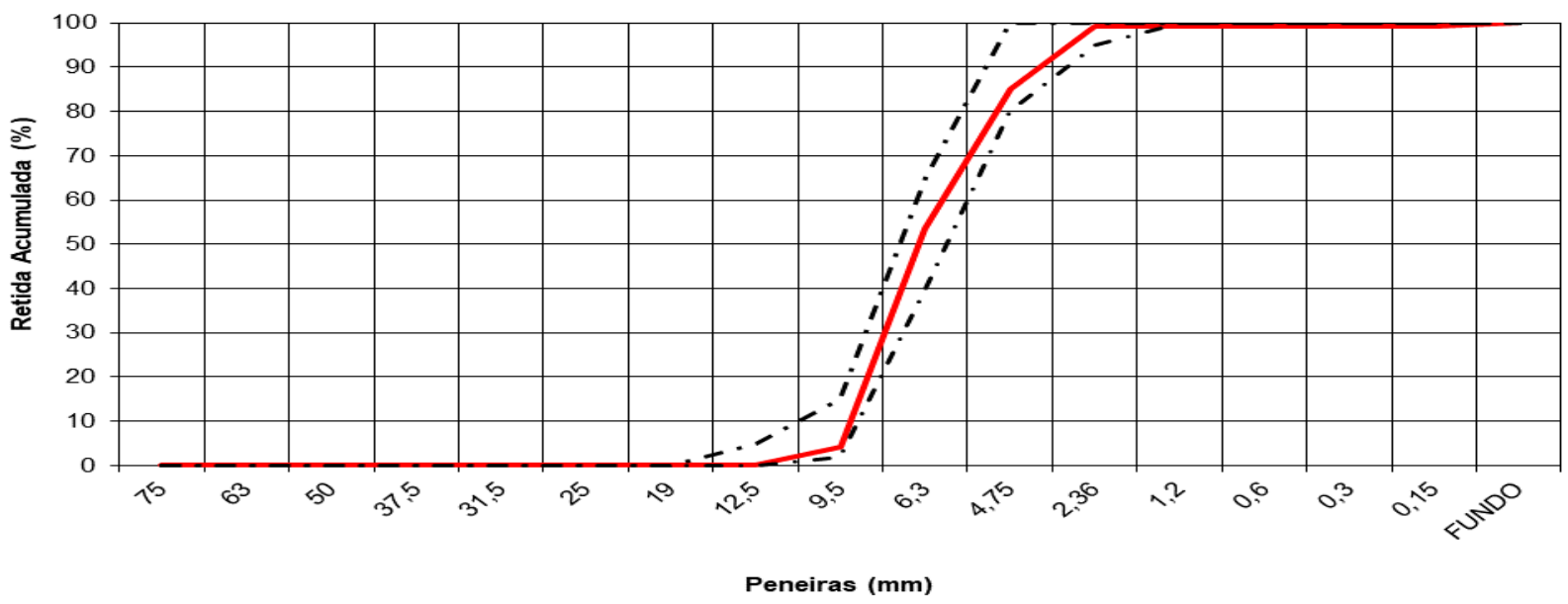

No Gráfico 1, a linha contínua representa o resultado granulométrico obtido pela amostra, onde é possível verificar que o pedrisco utilizado corresponde a brita 0 , também conhecida como pedrisco.

\subsubsection{Estado fresco}

De acordo com as classificações dos grautes no ensaio do slump flow, é possível observar que os três grautes atenderam aos limites para ser considerado auto adensável. Onde segundo a norma 15823:2017, o espalhamento de um auto adensável vai de 550 a $850 \mathrm{~mm}$ (SF1 a SF3). No Gráfico 2, é possível visualizar a influência do pedrisco e o desempenho dos grautes nesse tipo de ensaio. 
Gráfico 2 - Espalhamento (Slump flow)

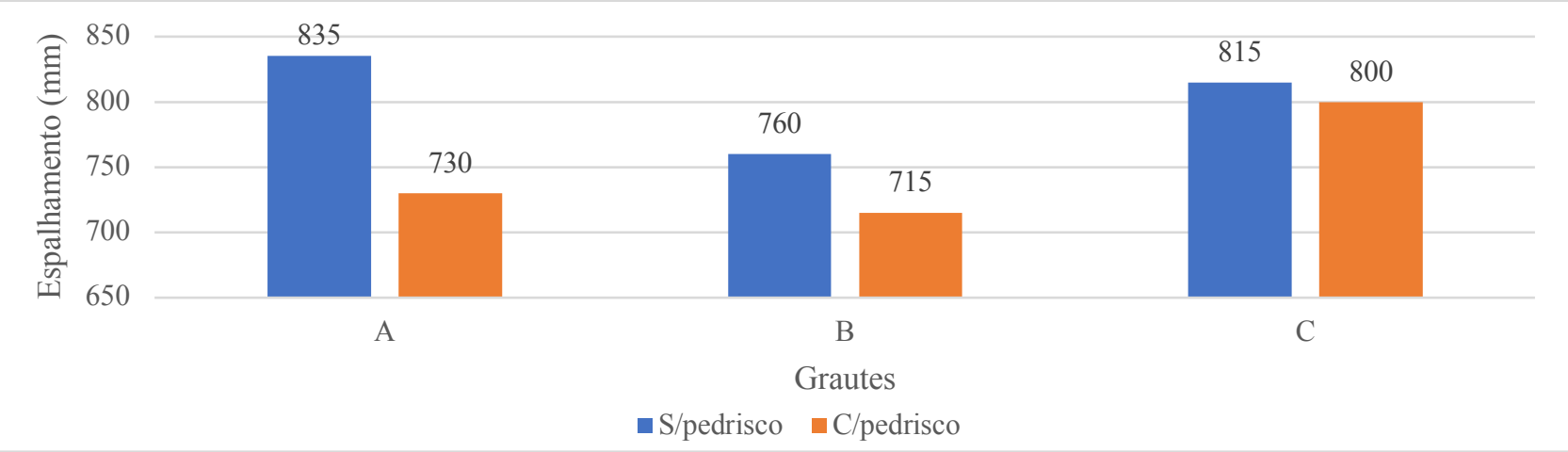

Verifica-se que o graute A foi o material que obteve resultados de espalhamento de $835 \mathrm{~mm}$ sem pedrisco (classe SF3). E com a adição do pedrisco, teve uma redução de 12,6\% (classe SF2). O graute B obteve um espalhamento de $760 \mathrm{~mm}$ (SF3) e a redução com o pedrisco foi de $5,9 \%$ (SF2). O graute C obteve $815 \mathrm{~mm}$ (SF3) e reduziu 1,8\% também com a adição do pedrisco (SF3).

Observou-se que a adição do pedrisco nesse ensaio reduziu o espalhamento para os três grautes. Em relação ao desempenho, todos os grautes com e sem a adição do pedrisco atenderam as especificações de um concreto auto adensável.

A Tabela 3 apresenta a análise dos resultados dos ensaios da Caixa L e Caixa U:

Tabela 3 - Classificação dos ensaios Caixa L e Caixa U

\begin{tabular}{c|c|c|c|c}
\hline Agregado & Grautes & Caixa L & Caixa U (mm) & Classe \\
\hline \multirow{3}{*}{ Sem pedrisco } & A & 0,96 & 4 & PL2 \\
\cline { 2 - 5 } & B & 0,97 & 0 & PL2 \\
\cline { 2 - 5 } & $\mathrm{C}$ & 1,00 & 5 & PL2 \\
\hline \multirow{3}{*}{ Com pedrisco } & $\mathrm{A}$ & 1,00 & 2 & PL2 \\
\cline { 2 - 5 } & $\mathrm{B}$ & 1,00 & 9 & PL2 \\
\cline { 2 - 5 } & $\mathrm{C}$ & 1,00 & 0 & PL2 \\
\hline
\end{tabular}

Os três grautes apresentaram habilidade passante e se classificaram como PL2, pois na caixa L foram atingidos valores superiores a 0,80 e na caixa $U$ obteve-se uma diferença menor que $30 \mathrm{~mm}$ entre os dois lados, seguindo as especificações da norma e atendendo os requisitos para serem considerados auto adensáveis.

Em relação à influência do pedrisco nesses ensaios, percebe-se que nos três grautes o desempenho foi semelhante ao ensaio sem a adição, tanto na caixa $L$ quanto na caixa $U$. Referente ao desempenho dos grautes, todos atingiram valores parecidos e foram eficazes nos quesitos fluidez, coesão e resistência à segregação.

Na Tabela 4 mostram-se os resultados obtidos pelo Funil V, onde é possível observar que tanto sem pedrisco quanto com a adição do pedrisco, se classificou como VF1, que sendo considerado auto adensável, é adequado para uma aplicação em elementos estruturais segundo a Norma NBR 15823 (2017).

Tabela 4 - Classificação do ensaio do funil V

\begin{tabular}{l|c|c|c}
\hline Agregado & Grautes & Funil V (s) & Classe \\
\hline \multirow{4}{*}{ Sem pedrisco } & $\mathrm{A}$ & 8,9 & VF2 \\
\cline { 2 - 4 } & $\mathrm{B}$ & 3,2 & VF1 \\
\cline { 2 - 4 } & $\mathrm{C}$ & 6,4 & VF1 \\
\hline \multirow{3}{*}{ Com pedrisco } & $\mathrm{A}$ & 7,9 & VF1 \\
\cline { 2 - 4 } & $\mathrm{B}$ & 4,3 & VF1 \\
\cline { 2 - 4 } & $\mathrm{C}$ & 4,7 & VF1 \\
\hline
\end{tabular}


No Gráfico 3 visualiza-se os resultados do funil V dado em segundo (s) e a análise da influência do pedrisco nesse ensaio.

Gráfico 3 - Resultados do ensaio no Funil V com e sem pedrisco.

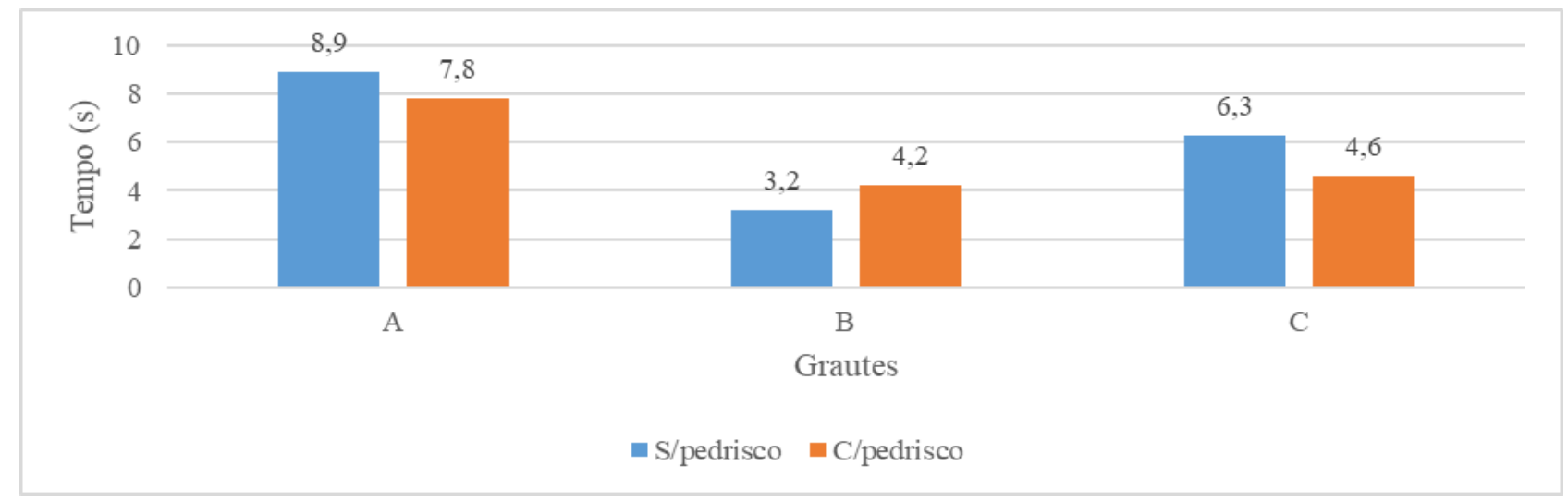

Observa-se no Gráfico acima que os grautes A e C apresentaram um tempo maior de escoamento sem a adição do pedrisco, já o graute $\mathrm{B}$ apresentou um tempo menor. Em relação aos grautes $\mathrm{A}$ e $\mathrm{C}$, o pedrisco influenciou na viscosidade do material, diminuindo o tempo de escoamento; já no graute $\mathrm{B}$, houve um aumento no tempo de escoamento. Ainda assim todos os grautes B e C classificaram-se como VF1 (tempo $\leq 8$ segundos) e o graute A sem pedrisco foi classificado como VF2 (tempo entre 9 e 25 segundos). Todos os grautes utilizaram o máximo de água permitida nas dosagens.

É possível observar nos resultados ensaiados acima que, segundo as normas da NBR referente ao concreto auto adensável, todos os três grautes apresentaram características semelhantes à fluidez e coesão de um CAA.

Além disto, a utilização dos ensaios normatizados de CAA (NBR 15823, 2017) mostraram-se adequados para avaliar a fluidez e segregação dos grautes sem e com pedrisco, detectando diferenças significativas entre os mesmos.

\subsubsection{Estado endurecido}

\subsubsection{Resistência à compressão}

Nos Gráficos, são apresentados os resultados de resistência à compressão sem e com pedrisco em comparação com as especificações fornecidas por cada fabricante. Os valores encontrados representam a média de dois corpos de prova para cada idade de ensaio.

\subsection{Graute A}

O Gráfico 4 mostra as resistências à compressão do graute $\mathrm{A}$ em comparação aos resultados especificados pelo fabricante. 
Gráfico 4 - Resistência a compressão do graute A sem pedrisco

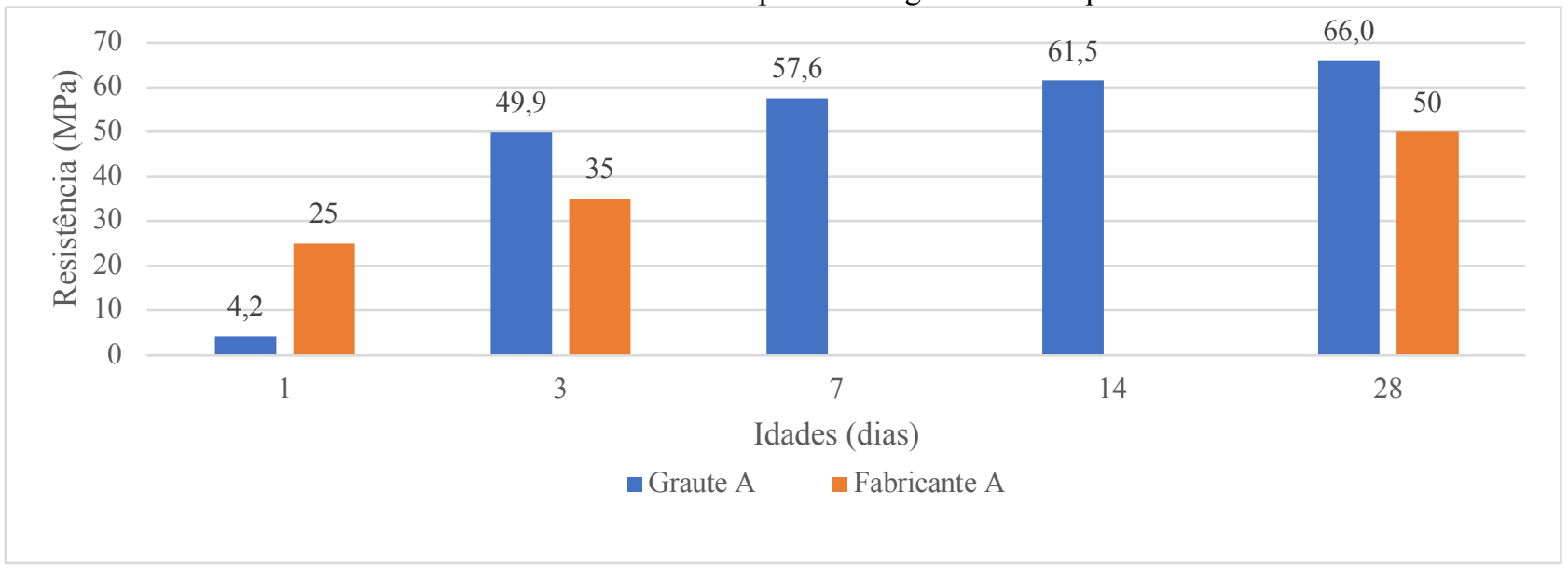

Observa-se que a resistência na idade de 1 dia não cumpriu com as especificações do fabricante atingindo apenas $17 \%$ do especificado; aos 3 dias obteve-se uma resistência à compressão de 42,6\% superior ao especificado e aos 28 dias um valor $32 \%$ maior que o especificado.

No Gráfico 5 é mostrado a influência do pedrisco nas resistências à compressão:

Gráfico 5 - Resistência à compressão do graute A

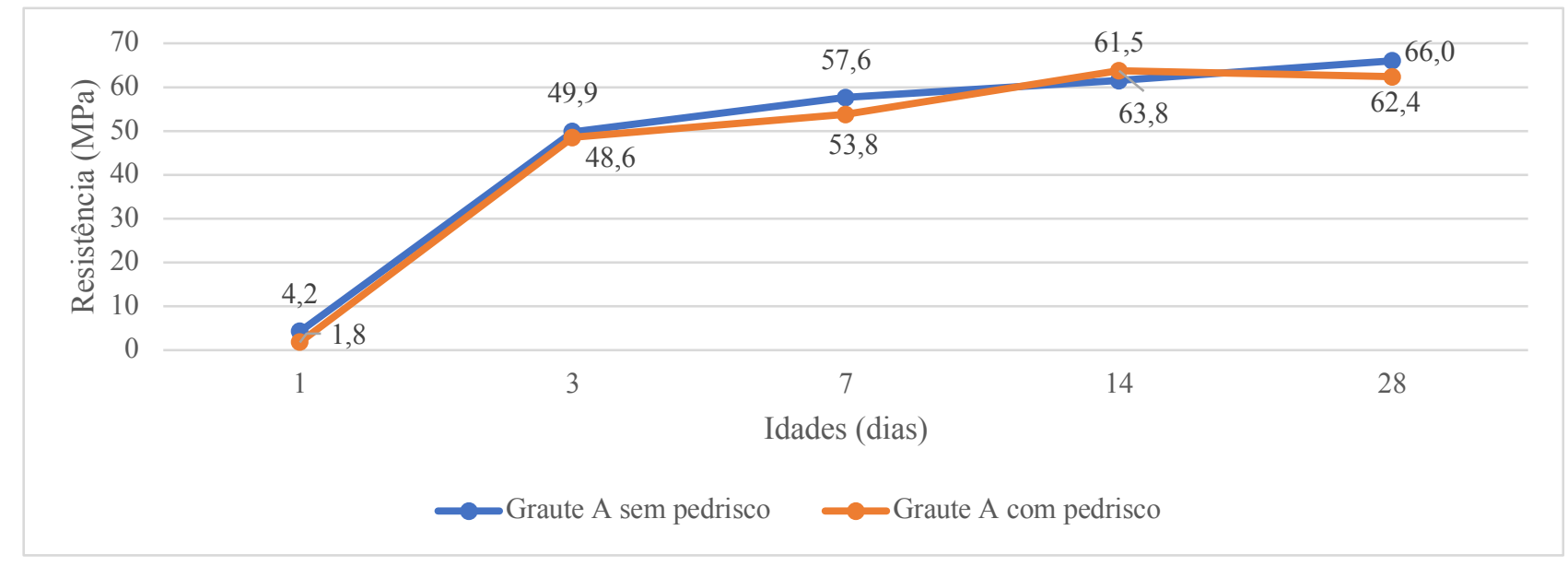

É possível observar que as resistências com a adição de pedrisco foram inferiores nas idades $1,3,7$ e 28 dias. Aos 28 dias, a influência da adição do pedrisco resultou em uma resistência à compressão 5,5\% inferior em relação ao graute $\mathrm{A}$ sem pedrisco.

Ainda, observa-se que a resistência de 1 dia com pedrisco também não atendeu ao mínimo especificado pelo próprio fabricante $(\geq 25 \mathrm{MPa})$.

\subsection{Graute B}

No Gráfico 6 são apresentadas as resistências à compressão do graute B em comparação com os resultados especificados pelo fabricante. 
Gráfico 6 - Resistência à compressão do graute B sem pedrisco

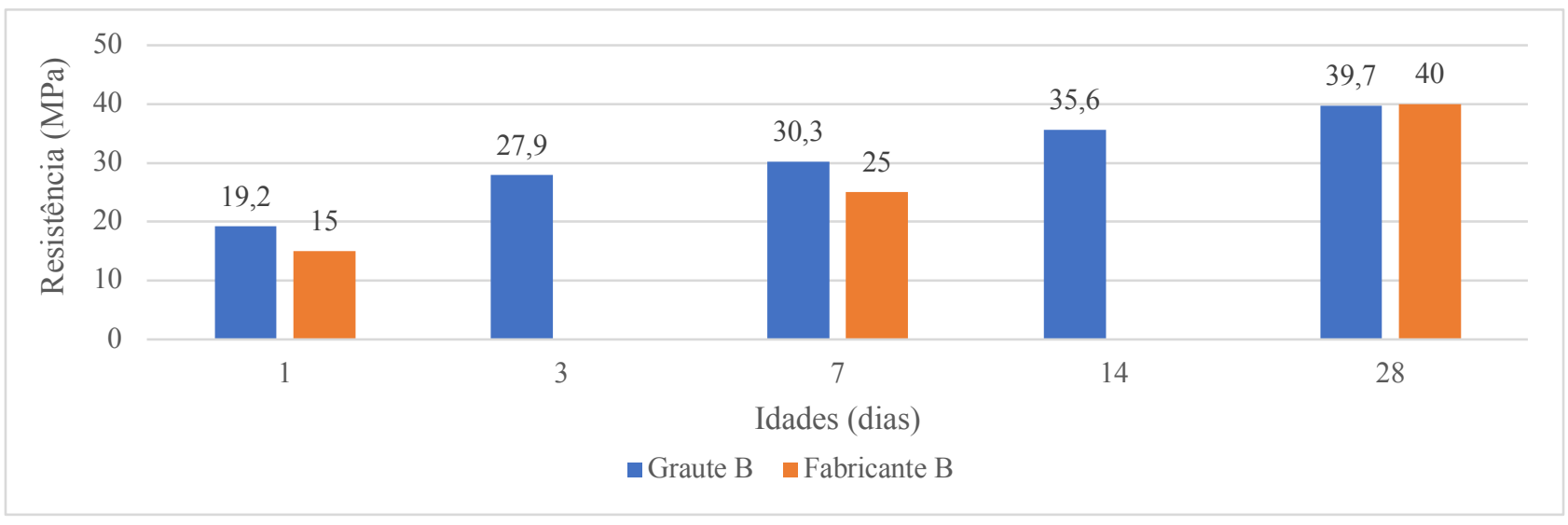

Observa-se que as resistências nas idades de 1 e 7 dias foram superiores em comparação com as resistências especificadas. Aos 28 dias o valor de resistência à compressão ficou próximo ao limite especificado, sendo $0,8 \%$ inferior.

No Gráfico 7 é mostrada a influência do pedrisco nas resistências à compressão:

Gráfico 7 - Resistência à compressão do graute B

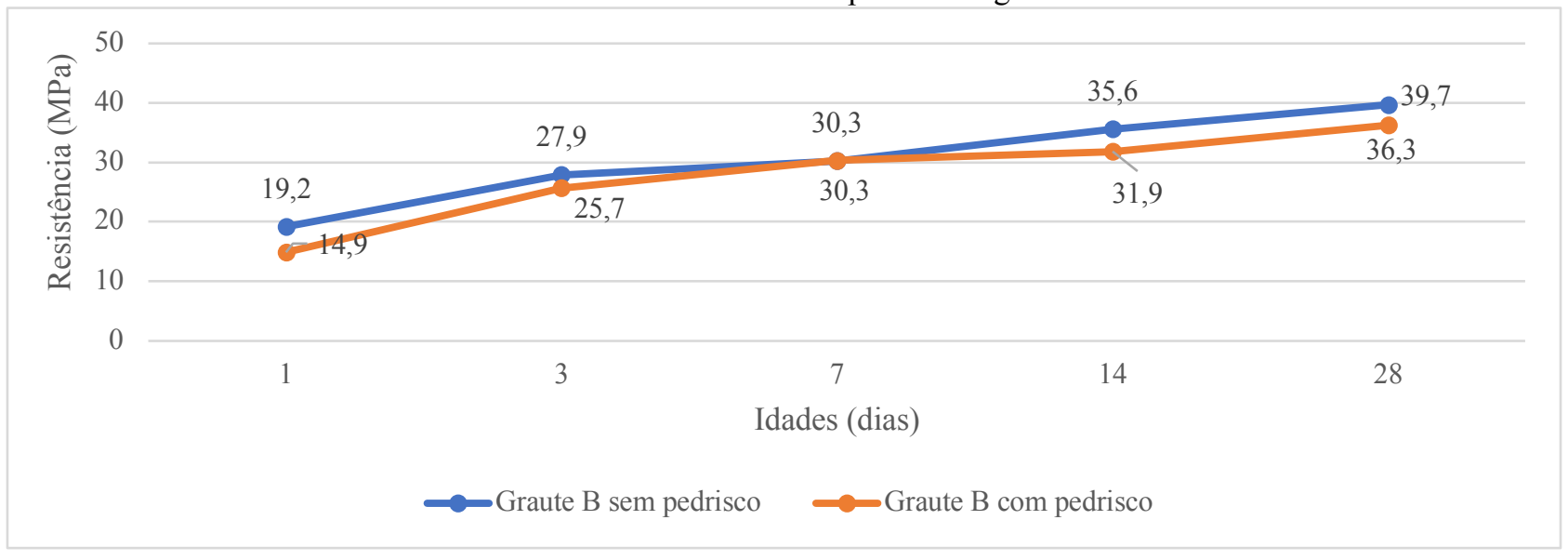

Observa-se que as resistências com a adição de pedrisco foram inferiores nas idades de 1, 3, 14 e 28 dias. Aos 28 dias a influência da adição do pedrisco resultou em uma resistência à compressão 8,6\% inferior.

Conclui-se, a partir dos resultados com e sem pedrisco, que o graute B não atende a resistência mínima de 28 dias ( $\geq 40$ $\mathrm{MPa})$.

\subsection{Graute C}

Mostram-se no Gráfico 8 as resistências à compressão do graute $\mathrm{C}$ em comparação aos resultados especificados pelo fabricante. 
Gráfico 8 - Resistência à compressão do Graute $\mathrm{C}$ sem pedrisco

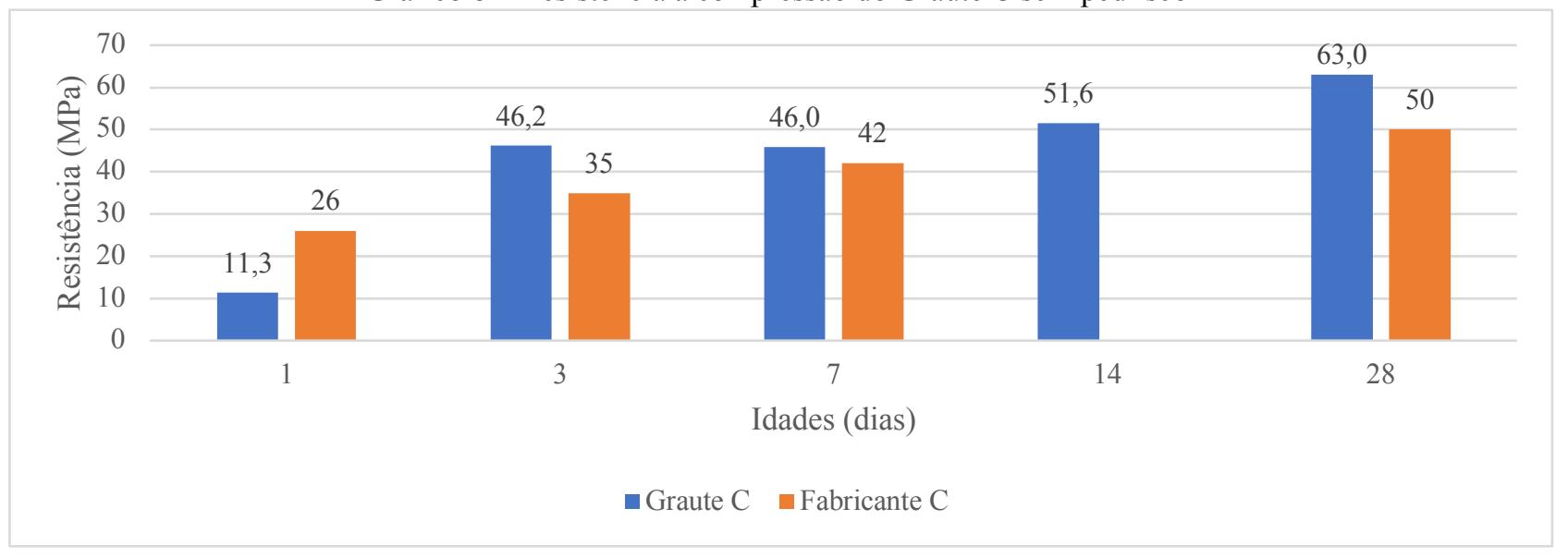

Observa-se que a resistência na idade de 1 dia não cumpriu com as especificações do fabricante, atingindo $56,5 \%$ do especificado; nas outras idades, as resistências foram superiores, atingindo aos 28 dias $20,6 \%$ a mais que o especificado pelo fabricante.

No Gráfico 9 é mostrada a influência do pedrisco nas resistências à compressão do graute C.

Gráfico 9 - Resistência à compressão do graute C

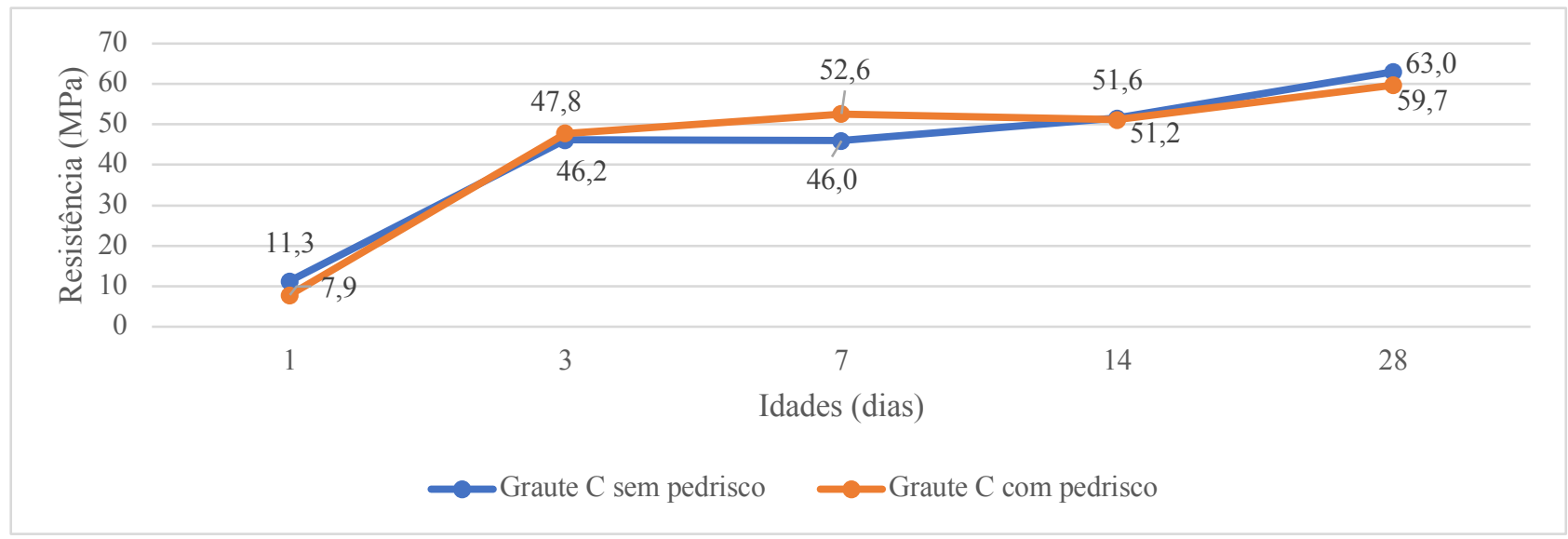

Observa-se que as resistências com a adição de pedrisco foram inferiores nas idades 1,14 e 28 dias. Aos 28 dias obteve uma redução de 5,24\%. Deve ser levado em conta que nas dosagens com pedrisco o graute C utilizou 0,25 litros a mais de água (de acordo com especificado com o fabricante).

Ainda, observa-se que a resistência de 1 dia com pedrisco também não atendeu ao mínimo especificado pelo próprio fabricante ( $\geq 26 \mathrm{MPa}$ ).

Em resumo, o graute $\mathrm{A}$ apresentou resultados de resistência à compressão superiores ao graute $\mathrm{C}$ (ambos especificados $\geq 50 \mathrm{MPa}$ aos 28 dias). Já o graute $\mathrm{B}$, que possui especificações de resistência à compressão mais baixa (40 MPa aos 28 dias) apresentou resistência inferior ao mínimo especificado para 28 dias, com e sem pedrisco.

Ainda assim, de acordo com Oliveira e Helene (2003), os grautes ensaiados nesse estudo atendem as resistências mínimas para ser considerado graute de reparo estrutural de resistência média (de $35 \mathrm{MPa}$ a $50 \mathrm{MPa}$ aos 28 dias).

Como é possível visualizar no decorrer dos gráficos, apesar das três marcas serem semelhantes, cada uma atingiu um valor específico, e verificou-se que ao adicionar o pedrisco, a resistência à compressão diminui, ou seja, sem adição de pedrisco os resultados de resistência à compressão tendem a ser superiores. 


\subsubsection{Resistência à tração por compressão diametral}

Na Tabela 5 visualizam-se os resultados detalhados das resistências à tração por compressão diametral aos 28 dias, que é a idade mais importante para os estudos de resistências. É apresentada a média dos resultados e a relação com a resistência à compressão.

Tabela 5 - Resultados resistência à tração por compressão diametral (28 dias)

\begin{tabular}{c|c|c|c}
\hline Material & Agregado & Resistência média $(\mathrm{MPa})$ & Relação $\mathrm{f}_{\text {ctd }} / \mathrm{f}_{\mathrm{c}}$ \\
\hline \multirow{2}{*}{ Graute A } & Sem pedrisco & 4,4 & $6,6 \%$ \\
\cline { 2 - 4 } & Com pedrisco & 4,5 & $7,2 \%$ \\
\hline \multirow{2}{*}{ Graute B } & Sem pedrisco & 4,1 & $10,4 \%$ \\
\cline { 2 - 4 } & Com pedrisco & 4,2 & $11,5 \%$ \\
\hline \multirow{2}{*}{ Graute C } & Sem pedrisco & 4,0 & $6,4 \%$ \\
\cline { 2 - 4 } & Com pedrisco & 4,5 & $7,5 \%$ \\
\hline
\end{tabular}

De acordo com a tabela, a média da relação fctd/fc dos três grautes sem pedrisco ficou na faixa de $7,8 \%$ e, com a adição, a média ficou em $8,7 \%$. Percebe-se que nesse ensaio o pedrisco influenciou positivamente nos valores de resistência à tração por compressão diametral.

Os grautes estudados atenderam as especificações mínimas de 2,5 MPa de resistências à tração por compressão diametral recomendadas por Tula, Oliveira e Helene (2003).

\subsubsection{Resistência à tração na flexão e compressão axial}

Os resultados de resistências à tração na flexão e compressão axial aos 28 dias dos CP's prismáticos estão detalhados na Tabela 6.

Tabela 6 - Resultados de tração por flexão e compressão axial (28 dias)

\begin{tabular}{c|c|c|c|c}
\hline \multirow{2}{*}{ Material } & $\begin{array}{c}\text { Adição } \\
\text { pedrisco }\end{array}$ & $\begin{array}{c}\text { Resistência à tração na } \\
\text { flexão média (MPa) }\end{array}$ & $\begin{array}{c}\text { Resistência à compressão } \\
\text { média (MPa) }\end{array}$ & $\mathrm{fctd} / \mathrm{fc}$ \\
\hline \multirow{2}{*}{ Graute A } & Sem & 12,3 & 73,9 & $16,6 \%$ \\
\cline { 2 - 5 } & Com & 12,1 & 72,0 & $16,8 \%$ \\
\hline \multirow{2}{*}{ Graute B } & Sem & 9,00 & 37,9 & $23,7 \%$ \\
\cline { 2 - 5 } & Com & 8,30 & 32,7 & $25,4 \%$ \\
\hline \multirow{2}{*}{ Graute C } & Sem & 10,4 & 61,7 & $16,9 \%$ \\
\cline { 2 - 5 } & Com & 8,50 & 62,5 & $13,6 \%$ \\
\hline
\end{tabular}

Referente à influência do pedrisco, visualiza-se que na flexão e na compressão axial os três grautes sofreram uma redução média de $9,2 \%$ a $5 \%$ respectivamente. A média da relação de resistência à tração na flexão em relação a resistência à compressão dos três grautes ficaram na faixa de $19,1 \%$ sem pedrisco e $18,6 \%$ com pedrisco.

\section{CONCLUSÕES}

Referente ao estado fresco:

- no slump flow, os três grautes atenderam os limites para serem considerados auto adensável (550 a $850 \mathrm{~mm}$ de abertura); o pedrisco influenciou reduzindo o espalhamento nos três grautes.

- nas caixas L e U todos atenderam os limites de auto adensável e não obtiveram variações com a adição do pedrisco.

- no funil $\mathrm{V}$, todos atenderam os limites de escoamento para serem considerados de auto adensáveis. Referente ao estado fresco dos grautes, todos cumpriram com as especificações de fluidez da Norma NBR 15823 (2017) e foram considerados auto adensáveis. 
Em relação aos resultados no estado endurecido:

- os valores obtidos de resistência à compressão aos 28 dias variaram de 39,7 MPa à $66 \mathrm{MPa}$ sem pedrisco; com a adição do pedrisco a redução média foi de $6,42 \%$; os três grautes se classificaram como grautes de reparo (de $35 \mathrm{MPa}$ a $50 \mathrm{MPa}$ aos 28 dias). Entretanto, o graute B não atingiu a resistência mínima de 28 dias especificada pelo próprio fabricante.

- os grautes $\mathrm{A}$ e $\mathrm{C}$ não atenderam a resistência mínima de 1 dias especificada pelos fabricantes.

- os valores de resistência à tração por compressão diametral variaram de 4,0 a 4,4 MPa sem pedrisco, com o pedrisco obteve-se um aumento de $5,74 \%$ nas resistências aos 28 dias.

- os valores de resistência à tração na flexão aos 28 dias variaram de $9 \mathrm{MPa}$ à $12,3 \mathrm{MPa}$ e a resistência à compressão axial variou de $37,9 \mathrm{MPa}$ à $73,9 \mathrm{MPa}$ sem pedrisco; com pedrisco, a tração reduziu em média $9,22 \%$ e a compressão axial reduziu em média $5 \%$.

- referente ao estado endurecido, nenhum dos três grautes cumpriram $100 \%$ as especificações de resistências dos fabricantes.

Em relação à influência do pedrisco:

- com base nos resultados obtidos, o pedrisco influenciou tanto nos ensaios no estado fresco, quanto nos ensaios no estado endurecido.

Este trabalho, assim como de Lopes (2018), evidenciam a necessidade de uma normatização para os grautes de reparo industrializados para se classificar com base nos ensaios próprios desses materiais, sem precisar adaptar ensaios que tratam de concreto ou argamassas.

Sugere-se a utilização dos ensaios normatizados de CAA (NBR 15823, 2017), pois se mostraram adequados para avaliar a fluidez e segregação dos grautes sem e com pedrisco, possibilitando detectar pequenas diferenças no comportamento dos grautes.

\section{REFERÊNCIAS}

ASSOCIAÇÃO BRASILEIRA DE NORMAS TÉCNICAS - ABNT. NBR NM 248:2003 Agregados - Determinação da composição granulométrica. Rio de Janeiro. 2003.

ASSOCIAÇÃO BRASILEIRA DE NORMAS TÉCNICAS - ABNT. NBR 5739 (2018): Concreto - Ensaio de compressão de corpos-de-prova cilíndricos. Rio de Janeiro. 2018.

ASSOCIAÇÃO BRASILEIRA DE NORMAS TÉCNICAS - ABNT. NBR 7211:2009 - Agregados para concreto Especificação. Rio de Janeiro. 2009.

ASSOCIAÇÃO BRASILEIRA DE NORMAS TÉCNICAS - ABNT. NBR 7222:2011 - Concreto e argamassa Determinação da resistência à tração por compressão diametral de corpos de prova cilíndricos. Rio de Janeiro. 2011.

ASSOCIAÇÃO BRASILEIRA DE NORMAS TÉCNICAS - ABNT. NBR 13279:2005 - Argamassa para assentamento e revestimento de paredes e tetos - Determinação da resistência à tração na flexão e à compressão. Rio de Janeiro. 2005.

ASSOCIAÇÃO BRASILEIRA DE NORMAS TÉCNICAS - ABNT. NBR 15823-1: Concreto auto adensável. Parte 1: Classificação, controle e recebimento no estado fresco. Rio de Janeiro. 2017.

ASSOCIAÇÃO BRASILEIRA DE NORMAS TÉCNICAS - ABNT. NBR 15823-2: Determinação do espalhamento, do tempo de escoamento e do índice de estabilidade visual - Método do cone de Abrams. Rio de Janeiro. 2017. 
ASSOCIAÇÃO BRASILEIRA DE NORMAS TÉCNICAS - ABNT. NBR 15961-1:2011-Alvenaria estruturalBlocos de concreto. Parte 1: Projeto. Rio de Janeiro. 2011.

ASSOCIAÇÃO BRASILEIRA DE NORMAS TÉCNICAS - ABNT. NBR 15823-4: Concreto auto adensável parte 4 - Determinação de habilidade passante Caixa L e Caixa U. Rio de Janeiro.2017.

ASSOCIAÇÃO BRASILEIRA DE NORMAS TÉCNICAS - ABNT. NBR 15823-5: Concreto auto adensável parte 5 - Determinação da viscosidade Funil V. Rio de Janeiro. 2017.

LOPES, J.M.P. Caracterização de grautes disponíveis para utilização nas obras da cidade do Natal - RN. 2018. Trabalho de Conclusão de Curso - Universidade federal do Rio Grande do Norte, Rio Grande do Norte, 2018.

TUlA, L; OLIVEIRA, P; OLIVEIRA, R. Grautes: Uma abordagem atual. Revista Téchne, São Paulo, PINI, n. 67, p. $62-68$, out. 2002

TUlA, L.; OLIVEIRA, P.; HELENE, P. Grautes de Reparo. Revista Téchne, São Paulo, PINI, ano 11, n. 77, p. 77 82, ago. 2003. 